\title{
Correction to: Streaming changepoint detection for transition matrices
}

\author{
Joshua Plasse $^{1}$ (D) $\cdot$ Henrique Hoeltgebaum ${ }^{2}$ (D) $\cdot$ Niall M. Adams $^{3}$
}

Received: 17 April 2021 / Accepted: 21 April 2021 / Published online: 25 May 2021

(C) The Author(s), under exclusive licence to Springer Science+Business Media LLC, part of Springer Nature 2021

\section{Correction to: Data Mining and Knowledge Discovery (2021) https://doi.org/10.1007/s10618-021-00747-7}

An error appeared in our paper entitled "Streaming changepoint detection for transition matrices" published in Data Mining and Knowledge Discovery. The Fig. 5 was rendered incorrectly in the article. The corrected Fig. 5 is shown below.

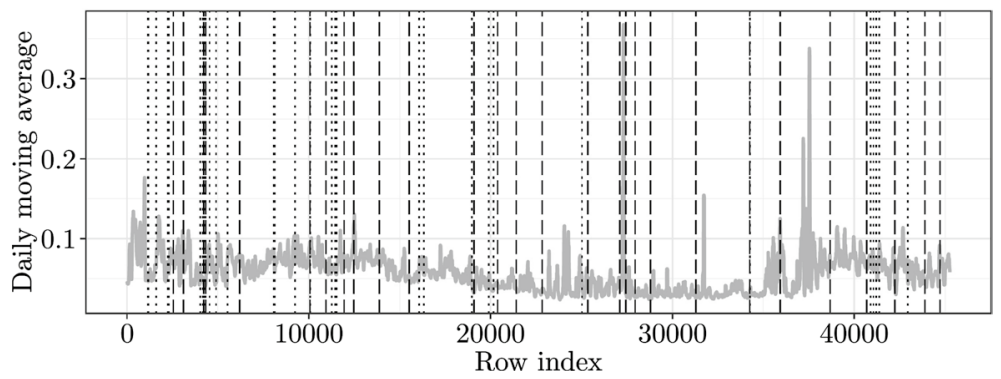

Plot of the 24-h moving average for the NSW electricity price. The vertical lines represent the detections made by ADEPT-M (dashed) and ADWIN (dotted).

The original article has been corrected.

Publisher's Note Springer Nature remains neutral with regard to jurisdictional claims in published maps and institutional affiliations.

The original article can be found online at https://doi.org/10.1007/s10618-021-00747-7.

Joshua Plasse

jp215@imperial.ac.uk

1 Department of Mathematics, Imperial College London, London, UK

2 Department of Mathematics, Imperial College London and The Alan Turing Institute, London, UK

3 Department of Mathematics and Data Science Institute, Imperial College London, London, UK 